\title{
ДИАЛОГ В ПОЛИКУЛЬТУРНО ОРИЕНТИРОВАННОЙ МУЗЫКАЛЬНОЙ ПОДГОТОВКЕ ДЕТЕЙ В УЧРЕЖДЕНИИ ДОПОЛНИТЕЛЬНОГО ОБРАЗОВАНИЯ
}

\author{
И. С. Кобозева
}

Мордовский государственный педагогический институт, Саранск

Объясняется понятие «поликультурность». Обосновываются необходимость воспитания у подрастающих поколений культуры межнационального общения и значимость в этом процессе диалога и образования. Рассматривается поликультурность в музыкальном образовании как средство воссоздания в содержании всех ценностей музыкальной культуры с целью целостного музыкально-культурного развития и самосовершенствования личности на основе национального и общечеловеческого идеала. Определяются ориентиры педагогической деятельности, направленные на развитие способности и потребности человека в творческом преобразовании окружающего музыкального мира в сочетании эмоционального и интеллектуального. Вводится понятие «национально-общечеловеческие ценностные ориентации», рассматривается их структура. Представлены результаты мониторинга педагогической практики, на основании которого определены проблемы современного поликультурного образования, связанные с процессом формирования у школьников навыков межкультурного сотрудничества и поликультурного диалогового взаимодействия, необходимых для музыкальной деятельности в условиях культурного многообразия России и всего мирового пространства. Рассматривается поликультурное музыкальное образование, определяющее новую область содержания образования школьников в учреждении дополнительного образования. Утверждается, что неотъемлемой частью поликультурного музыкального образования является поликультурно ориентированная музыкальная подготовка. Сделаны выводы о возможности ее реализации в учреждении дополнительного образования в соответствии с разработанными педагогическими условиями.

Ключевые слова: культура, личность, общество, поликультура, поликультурное музыкальное образование, поликультурно ориентированная музыкальная подготовка, ценностное отношение, начиональные и общечеловеческие ценности музыкальной культуры.

Современная российская цивилизация характеризуется свободным мировоззрением, признанием прогрессивных взглядов и ценностей, стремлением к межкультурному взаимодействию одного народа с другим, к сохранению традиционных ценностей, чувства ответственности и дружбы с другими народами и странами планеты, чтобы занимать достойное место в ансамбле стран мира посредством диалога и уважения. Это становится возможным, когда создание многокультурного образа страны продиктовано внутренней потребностью каждого ее гражданина. И потому поликультурная ориентированность в дальнейшем цивилизационном развитии России, исторически сложившейся как многонациональное государство, представляется одним из главных условий ее жизнеспособности.

Поликультурность базируется, как известно, на признании множества, многообразия культур, на их познании, уважении, принятии ценностей национальной, российской и мировой культуры. Сохранение и развитие культурного многообразия народов, укрепление единства и духовной общности многонационального народа России указаны среди 
целей и приоритетных направлений Стратегии государственной национальной политики Российской Федерации на период до 2025 года. Настоящий документ, «учитывая многовековой историко-культурный опыт становления и развития российской государственности, основанный на взаимодействии и сотрудничестве народов, населяющих Российскую Федерацию», определяет необходимость воспитания у детей и учащейся молодежи «культуры межнационального общения, основанной на уважении чести и национального достоинства граждан, традиционных российских духовно-нравственных ценностей» [1].

Данный контекст повышает значимость приобщения детей к культуре различных народов, наций, к международным нормам межкультурного взаимодействия, к общечеловеческим, национальным и этническим ценностям. Данная сторона социальной жизни через воспитание и обучение предполагает, по мнению А. Н. Джуринского, «сопряжение культурных ценностей всех участников межкультурного диалога, создание общего культурного национального пространства, где каждый человек обретает социальный и этнический статус, определяет принадлежность к тем или иным языкам и субкультурам» [2, с. 16]. Этот приоритет педагогики и образования служит «опорой духовности и очагом приобретения национальных и общечеловеческих культурных ценностей» [3, с. 188].

Сказанное находит отражение в таких официальных основополагающих документах, как Федеральный закон «Об образовании в РФ», распоряжении Правительства Российской Федерации от 29 декабря 2014 г. № 2765-Р, устанавливающем положение федеральной целевой программы развития образования на 2016-2020 гг. [4, 5].

Многомерность и неоднозначность процессов самоопределения и самореализации человека в пространстве современной музыкальной культуры обусловливают закономерный характер поиска ответов на комплекс вопросов о том, как и почему человек не только развивается в процессе познания и присвоения национальных и общечеловеческих ценностей, но и вносит в мировую музыкальную культуру общества свой личностный вклад. «Движение от семьи и родного дома - к стране и миру, от субъекта Федерации - к России и земному шару представляется вполне естественным», - гласит концепция развития поликультурного образования в Российской Федерации [6].

Развитие интеграционных процессов в современном мире явилось детерминантой развития в музыкальном образовании поликультурности. Поликультурность является средством вхождения музыкального образования в социокультурный контекст, отражающим «потребность и способность воссоздавать в своем содержании все ценности музыкальной культуры и дополнять эту целостность личностно-ценностным отношением» [7, с. 13]. Последнее в музыкальном образовании - «это цель, которая определяет путь целостного музыкально-культурного развития и самосовершенствования личности [7, с. 13].

Понимание сущности, целей, функций поликультурного музыкального образования исходит из воззрений Н. Рериха о «единении культур», создающих благотворное сотрудничество людей, из концепций Н. Данилевского, Э. Мейлера, А. Тойнби и др. о целостности культуры.

Для осознания роли поликультурного музыкального образования в становлении личности значимым представляется убеждение П. Ф. Каптерева о народности и общечеловечности в педагогической деятельности. Подчеркивая взаимосвязь национального и общечеловеческого в педагогике, он писал, что «нужно обратиться не к одному народу, а ко многим, рассмотреть их идеалы и ценными чужими свойствами пополнить недостатки своего национального идеала; народное нужно сочетать с инородным, со всенародным и общечеловеческим» [8]. 
Кобозева И. С. Диалог в поликультурно ориентированной музыкальной подготовке детей...

При рассмотрении проблемы поликультурности в музыкальном образовании следует исходить из развития и взаимосвязи, т. е. реальной диалектики единичного - особенного общего и всеобщего [9]

Национально-культурное в музыкальном образовании соответствует категории особенного, которая раскрывает специфику выражения, проявления и реализации общего в единичном и через единичное. Наибольшее значение в развитии, а не в формировании поликультурности играют не особенные, региональные, а общие - государственные и всеобщие - общечеловеческие, инвариантные ценности музыкальной культуры. Единичное в множественности, которое создается музыкальной культурой, выполняющей одну из основных своих функций - функцию объединения, коммуникации, подтверждает мысль Н. Рериха о том, что Россия - это единство в разности, полихромия, полифония. Но проблема в том, как все эти ценности музыкальной культуры общества в целостности оформляются в музыкальной культуре личности.

Для педагогики музыкального образования они интерпретируются в таких ориентирах деятельности, как развитие способности и потребности человека в творческом преобразовании окружающего музыкального мира в сочетании эмоционального и интеллектуального, что, по мнению Н. Б. Кухаревой, «открывает широкую возможность формирования у учащихся интереса и потребности в общении с музыкальным искусством своего народа и приобщения к музыкальной культуре других народов» [10, с. 34-35].

Музыка, которая, как писал Б. Асафьев, «не выдумывается, а плавится из реальности», являясь способом познания и способом оценки мира, сосредотачивает в себе ценностные и смысловые элементы различных культур. Музыкальное искусство помогает человеку научиться видеть и чувствовать вечно присутствующую в мире истину, гармонию, красоту. Именно поэтому одним из ведущих принципов музыкального образования в условиях поликультурной образовательной среды выступает принцип культуросообразности $[11$, c. 235$]$.

Отсюда, по мнению ученых, важнейшей задачей музыкального образования становится «развитие у подрастающих поколений таких личностных качеств, которые наиболее отчетливо проявляются во взаимоотношениях людей, в межкультурном общении между представителями разных народов, населяющих регионы страны и мира» [12].

Возникновение представлений народов друг о друге, представлений о «своих» и «чужих» - сложный и противоречивый процесс, связанный с необходимостью развития диалогичности личности, делающей в итоге человека, способного к диалогу культур.

Теоретическим и практическим вкладом в педагогическую теорию нашего времени являются труды и деятельность отечественных исследователей М. М. Бахтина, Н. А. Бердяева, В. С. Библера, понимающих феноменологию культуры как миссию всеобщего человеческого общения и рассматривающих диалог как условие понимания личности [13, с. 156$157 ; 14]$. Данный императив фиксирует «отношение одного человека к другому как составной части единого человечества» [15].

Закономерности диалога «человек - музыкальная культура» опираются на обобщение опыта человеческого общения, частным случаем которого является музыкальное образование, которое затрагивает проблемы межкультурного диалога не только в музыкальной культуре общества, но и в музыкальной культуре личности будущего учителя и ученика - культуре диалога.

В музыкально-образовательной практике здесь целесообразно говорить о диалоге при обучении на основе этнокультурных ценностей (владение фольклором), при развитии музыкальной культуры личности на основе национальных (владение музыкальной культурой 
региона или российской музыкальной культурой - имеется в виду поликультурность в государственном значении) и общечеловеческих ценностей (речь идет о развитии поликультурности в планетарном масштабе).

Глобальность и масштабность функционирования ценностей национальной музыкальной культуры, равно как и общечеловеческих ценностей, в конкретном обществе определяются тем, что они, словами Е. В. Назайкинского, «охватывают как индивидуальный, личностный, жизненный опыт человека, формируя („в онтогенезе“) содержательный словарь разнообразнейших звуковых ассоциаций, так и социальный, исторический, нормирующий опыт, складывающийся „в филогенезе“ и передающийся в тех или иных формах и дозах каждому члену общества, но, кроме того, также и биологический опыт всего живого» [16, c. 160].

Ценность, как обозначено в гуманитарной энциклопедии, - «одна из основных понятийных универсалий в системе философских и гуманитарных дискурсов, обозначающая в самом общем виде, во-первых, положительную или отрицательную значимость какого-либо объекта или явления действительности, в отвлечении от его экзистенциальных и качественных характеристик (предметные ценности), во-вторых, нормативную (оценочную) сторону явлений общественного сознания (субъектные ценности)» [17].

Музыкально-культурные ценности, будь то национальные или общечеловеческие, это, по словам Н. Бердяева, «ценности, порождаемые творчеством» [14, с. 164]. К этим ценностям относятся музыкальные произведения фольклорной и профессиональной традиции, созданные творческим гением народа (фольклор) и композитора. В педагогике ценность, по свидетельству А. М. Новикова, это «предмет, явления или их свойства, которые нужны членам определенного общества или отдельной личности в качестве средств удовлетворения своих материальных и духовных потребностей и интересов, направленных на достижение общественных целей» [18, с. 255-256].

Ценности, отражая содержательную сторону отношения личности к предмету, способствуют совершенствованию личности человека. Вне проведения взаимосвязи между культурными ценностями и присваивающими их людьми музыкальная культура общества лишается своего гуманистического смысла. По мнению М. М. Бахтина, «эстетическое творчество преодолевает познавательную и этическую бесконечность и заданность тем, что относит все моменты бытия и смысловой заданности к конкретной данности человека - как со-бытие его жизни, как судьбу его» [13, с. 156-157]. Художественные ценности концентрируют в себе разнообразие индивидуального бытия людей, их существование и нравственные искажения, а также образцы самостоятельного решения мировоззренческих и практических проблем.

Фактор личностного отношения к ценностям является показателем разновидностей типов классификации ценностей, их иерархии. Например, этнической культуры, это развитие этнокультурных ценностей, народного искусства.

Формирование ценностного отношения человека к национальной и общечеловеческой культуре в условиях поликультурного музыкального образования напрямую связано с такой направленностью личности, как ценностные ориентации. Ценностные ориентации как «избирательное отношение человека к материальным и духовным ценностям, выраженное в его поведении, деятельности», мотивируют деятельность человека, являются «факторами, непосредственно вызывающими побуждение человека к действию» [18, с. 256-257].

Сказанное, с нашей точки зрения, позволяет говорить о необходимости формирования у обучающихся национально-общечеловеческих ценностных ориентаций. Последние мы связываем со сферой личностно значимых отношений в системе «человек - культура - об- 
Кобозева И. С. Диалог в поликультурно ориентированной музыкальной подготовке детей...

щество», которые проявляются в способности человека к трансформации национальных и общечеловеческих музыкальных ценностей в личностно значимые в диалоговом режиме взаимодействия различных культур с гносеологических, логических, семантических позиций.

Таким образом, национально-общечеловеческие ценностные ориентации человека воплощают в себе, во-первых, музыкальное искусство фольклорной традиции, отражающее полиэтнический национальный состав современных регионов; во-вторых, профессиональное музыкальное искусство конкретного региона и отечественное музыкальное искусство в целом и, в-третьих, народное и профессиональное музыкальное искусство зарубежных стран и народов.

В соответствии с формулировкой понятия мы определяем структуру национально-общечеловеческих ценностных ориентаций, включающую восприятие личностью национальных и общечеловеческих ценностей музыкальной культуры; эмоциональное переживание, заложенных в него образов; практическая творческая музыкальная деятельность в содержательном поле национальных и общечеловеческих ценностей музыкальной культуры, создающая условия для формирования эмоциональной основы национально-общечеловеческих ценностных ориентаций посредством эмоционального переживания музыкальных образов. Подобная организация практической творческой музыкальной деятельности в содержательном поле национальных и общечеловеческих ценностей музыкальной культуры выступает в качестве острейшей проблемы современной педагогики музыкального образования.

Существенная роль в формировании поликультурного музыкального образования детей отводится системе общего и дополнительного образования. Общеобразовательные, детские музыкальные школы, детские школы искусств, также другие образовательные учреждения предоставляют учащимся возможность для развития творческой деятельности и самовыражения; являются источником формирования национально-общечеловеческих ценностных ориентаций, морально-нравственных приоритетов и духовных ценностей личности.

Однако практика показывает, что попытка решения вопросов поликультурного образования и воспитания школьников, формирования у них навыков межкультурного сотрудничества и поликультурного диалогового взаимодействия, необходимых для музыкальной деятельности в условиях культурного многообразия, в массовом опыте общеобразовательной школы, учреждений дополнительного образования в области искусства осуществляется не на должном уровне. Это направление в работе образовательных организаций сопряжено с рядом трудностей социокультурного (динамичность, сложность, многообразие процессов взаимодействия средствами музыки), психологического (разнородность музыкальных интересов учащихся - представителей разных национальностей, конфессий и т. д.), педагогического характера (отсутствие методических ориентиров в осуществлении рассматриваемого процесса и др.). В реальной образовательной практике педагоги уделяют недостаточное внимание развитию обозначенных качеств, отдавая в триединстве - обучения, воспитания и развития - приоритет лишь одному из процессов.

Вместе с тем педагогическая общественность едина во мнении, что музыкальная подготовка, ориентированная на овладение обучающимися совокупностью знаний, умений и навыков, дающих возможность подрастающему поколению жить в поликультурной общественной среде, уступает место вокально-хоровой или инструментально-исполнительской подготовке детей.

Отсюда на первый план выдвигается проблема поликультурно ориентированной музыкальной подготовки, включающей такие аспекты, как формирование у детей поликультурной 
музыкальной грамотности и овладение школьниками навыками национального вокальнохорового и инструментально-исполнительского стиля - «овладение общечеловеческими и национальными ценностями музыкальной культуры посредством освоения музыкальных произведений разных стилей, жанров и форм» [19, с. 176].

Поликультурная музыкальная грамотность, т. е. понимание иной музыкальной культуры, выступает неотъемлемой частью жизни в поликультурном обществе, что обусловливает необходимость ее формирования у подрастающих поколений, поскольку обучающиеся должны быть подготовлены к уважению различных традиций и культур.

Национальный исполнительский стиль как способ эмоционально-ценностного познания музыкального произведения проявляет себя в музыкально-исполнительской деятельности, в качестве способа трактовки содержания музыкального произведения, иными словами, это процесс проникновения в культурно-историческое бытие исполняемого нотного текста, расшифровки звуковых (интонационных, метроритмических, гармонических и пр.) и фактурных смыслов сочинения самодеятельного (фольклорное произведение) или профессионального композитора. Исследование смысловой структуры музыкального произведения сможет во многом оказать влияние на формирование национально-общечеловеческих ценностных ориентаций подрастающего человека.

Из сказанного явствует, что поликультурно ориентированная музыкальная подготовка представляет собой сложное образование, которое включает в себя знание, понимание, переживание, осмысление ценностей музыкальной культуры того или иного этноса или народа.

Учреждения дополнительного образования, которые рассматриваются как важнейшая составляющая единого образовательного пространства Российской Федерации, - это значительный и важный компонент системы образования, влияющий на эффективность исследуемого процесса. Данное утверждение связано с рядом обстоятельств.

Во-первых, целью дополнительного образования, в структуру которого входят детские музыкальные школы, школы искусств и т. п., становится закрепленное законодательными документами приобщение учащихся к музыкально-культурным ценностям разных народов, стран и континентов.

Во-вторых, определились ориентиры музыкально-образовательной деятельности, направленные на развитие поликультурной личности, осознающей и свою этническую принадлежность, и принадлежность других людей к своим культурам.

В-третьих, утверждается практическая ориентированность образования.

В-четвертых, дети изучают национальную культуру, знакомятся с традициями и культурными особенностями региона, России, других стран начиная с младшего школьного возраста, богатого скрытыми возможностями музыкального развития, которые важно своевременно улавливать и поддерживать.

Следовательно, именно музыкально-культурное ценностное наследие, объединяющее представителей различных национальностей, должно быть положено в основу поликультурно ориентированной музыкальной подготовки в учреждениях дополнительного образования и являться одним из системообразующих содержательных компонентов при выстраивании педагогической работы.

Исходя из представленной характеристики поликультурно ориентированной музыкальной подготовки, необходимо выделить ряд организационно-педагогических условий, реализация которых способна обеспечить целостность педагогического процесса в учреждении дополнительного образования в ходе поликультурного развития учащихся: 
Кобозева И. С. Диалог в поликультурно ориентированной музыкальной подготовке детей...

- организация поликультурной музыкально-образовательной среды на основе внедрения поликультурно ориентированной музыкальной подготовки в организации музыкальной деятельности учащихся с учетом их возрастных особенностей;

- отбор содержания поликультурного музыкального образования на основе внедрения разработанных инновационных программ;

- разработка инновационных программ, направленных на поликультурное образование, в опоре на развитие национально-общечеловеческих музыкальных ценностных ориентаций;

- использование нетрадиционных технологий обучения, учитывающих необходимость эмоционально-личностного переживания и художественно-образного восприятия этнокультурных, национально-культурных и общечеловеческих ценностей музыкальной культуры;

- дополнение и совершенствование поликультурного содержания базовых музыкальных дисциплин в условиях дифференцированного, углубленного и ориентированного на творчески деятельностную самореализацию личности учащегося его обучения, воспитания и развития;

- внедрение в музыкально-образовательный процесс различных организационных форм обучения (факультативы, кружки и т. д.);

- использование тематически обоснованной формы повышения квалификации педагогов в системе научно-практических и обучающих семинаров, мастер-классов, лекториумов, научных школ, дискуссионных площадок и т. п.

В заключение подчеркнем, что не вызывает сомнения значимость поликультурно ориентированной музыкальной подготовки в учреждении дополнительного образования и в других образовательных организациях в целом как воспитательного инварианта, выступающего ценностно-смысловой основой формирования личности.

Исследование выполнено в рамках гранта на проведение научно-исследовательских работ по приоритетным направлениям научной деятельности вузов - партнеров по сетевому взаимодействию (федеральное государственное бюджетное образовательное учреждение высшего образования «Южно-Уральский государственный гуманитарнопедагогический университет» и Мордовский государственный педагогический институт им. М. Е. Евсевьева) по теме «Теоретико-методические основы дополнительного образования детей средствами искусства в условиях поликультурного региона», рег. № 2019-08-01, дата рег.: 25.09.2019.

\section{Список литературы}

1. Указ Президента Российской Федерации о внесении изменений в Стратегию государственной национальной политики Российской Федерации на период до 2025 года, утвержденную Указом Президента Российской Федерации от 19 декабря 2012 г. № 1666. URL: http://docs.cntd.ru/document/902387360 (дата обращения: 14.11.2019).

2. Джуринский А. Н. Поликультурное образование в многонациональном социуме. М.: Юрайт, 2019. 257 с.

3. Джуринский А. Н. Развитие образования в современном мире. М.: ВЛАДОС, 1999. 200 с.

4. Распоряжение Правительства Российской Федерации от 29 декабря 2014 г. № 2765-Р, утверждающее концепцию федеральной целевой программы развития образования на 2016-2020 годы. URL http://government.ru/docs/16479/ (дата обращения: 14.11.2019).

5. Федеральный закон «Об образовании в РФ» от 29.12.2012 № 273-Ф3. URL http://www.consultant.ru/document/cons_doc_ LAW_140174/ (дата обращения: 14.11.2019).

6. Концепция развития поликультурного образования в Российской Федерации. M., 2010. URL: http://www.mon.gov.ru (дата обращения: 18.11.2019). 
7. Кобозева И. С. Музыкальное образование в современном поликультурном контексте // Ярославский пед. вестн. 2012. T. II, № 3. C. 10-13.

8. Каптерев П. Ф. Избранные педагогические сочинения. М.: Педагогика, 1982. 704 с.

9. Кобозева И. С. Поликультурность в аксиологическом контексте современного музыкального образования // Педагогическая наука и практика: мировые, российские и региональные тенденции развития: материалы междунар. науч.практ. конф.: в 4 ч. Саранск: Мордов. гос. пед. ин-т, 2009. Ч. IV. С. 168-171.

10. Кухарева Н. Б. Музыкальное сознание учителя в процессе поликультурного образования // Педагогика музыкального образования: проблемы и перспективы развития: материалы II Междунар. очно-заоч. науч.-практ. конф. Нижневартовск: Изд-во Нижневарт. гуманит. ун-та, 2009. С. 34-37.

11. Асафьев Б. В. Музыкальная форма как процесс. Л.: Музыка, 1971. 376 с.

12. Kobozeva I. S., Mironova M. P., Chinyakova N. I. Communicative Competency as Teacher's Integrative Ability for Musical Communication // Asian Social Science. 2015. Vol. 11, № 8. P. 37-43.

13. Бахтин М. М. Творчество Франсуа Рабле и народная культура Средневековья и Ренессанса. М.: Худож. лит., 1990. $543 \mathrm{c}$.

14. Бердяев Н. А. Смысл истории. М.: Мысль, 1990. 177 с.

15. Библер В. С. Культура: диалог культур // Вопросы философии. 1989. № 6. С. 33-38.

16. Назайкинский Е. В. О психологии музыкального восприятия. М.: Музыка, 1972. 384 с.

17. Гуманитарная энциклопедия // Гуманитарные технологии: аналитический портал. URL: https:/gtmarket.ru/encyclopedia/ (дата обращения: 14.11.2019).

18. Новиков А. М. Педагогика: словарь системы основных понятий. М.: ИЭТ, 2013. 268 с.

19. Чинякова Н. И., Кобозева И. С., Плохов А. В. Музыкальное исполнительство и образование сквозь призму подготовки учителя // Ярославский пед. вестн. 2016. № 3. С. 175-180.

Кобозева Инна Сергеевна, доктор педагогических наук, профессор, Мордовский государственный педагогический институт им. М. Е. Евсевьева (ул. Студенческая, 11a, Саранск, Республика Мордовия, 430007). E-mail: kobozeva_i@mail.ru

SPIN-код: 6701-9500.

Материал поступил в редакциию 04.12.2019.

DOI 10.23951/2307-6127-2020-1-27-36

\section{DIALOGUE IN MULTICULTURAL MUSIC TRAINING OF CHILDREN IN THE SUPPLEMENTARY EDUCATION INSTITUTION}

\section{S. Kobozeva}

Mordovian State Pedagogical Institute named after M. E. Evsevyev, Saransk, Republic of Mordovia, Russian Federation

The content of the concept "multiculturalism" has been given. The need to educate the younger generations of a culture of inter-ethnic communication and the importance of education in this process is justified. Multiculturalism in music education is considered as a means to recreate in the content of all values of musical culture with the aim of holistic musical and cultural development and self-improvement of the person on the basis of the national and universal ideal. The guidelines of pedagogical activity aimed at developing the ability and needs of a person in the creative transformation of the surrounding musical world in a combination of emotional and intellectual are defined. The concept of "national-universal value orientations" is introduced, their structure is considered. The results of monitoring of pedagogical practice are presented, on the basis of which problems of modern multicultural education related to the process of formation of intercultural cooperation and multicultural dialogue skills of schoolchildren, necessary for musical activity in conditions of cultural 
Кобозева И. С. Диалог в поликультурно ориентированной музыкальной подготовке детей...

diversity of Russia and the whole world space are determined. Multicultural music education is being considered, which defines a new area of school education in the institution of supplementary education. Multicultural music training is said to be an integral part of multicultural music education. Conclusions have been drawn on the possibility of its implementation in the institution of additional education in accordance with the developed pedagogical conditions.

It justifies the need to educate the younger generations of a culture of interethnic communication and the importance of dialogue and education in this process.

Keywords: culture, personality, society, multicultural music education, multicultural music training, value attitudes, national and universal values of music culture.

\section{References}

1. Ukaz Prezidenta Rossiyskoy Federatsii o vnesenii izmeneniy v Strategiyu gosudarstvennoy natsional'noy politiki Rossiyskoy Federatsii na period do 2025 goda, utverzhdennuyu Ukazom prezidenta Rossiyskoy Federatsii ot 19 dekabrya $2012 \mathrm{~g}$. no. 1666 [Decree of the President of the Russian Federation on Amendments to the Strategy of the State National Policy of the Russian Federation for the Period up to 2025, approved by the Decree of the President of the Russian Federation of December 19, 2012 no. 1666] (in Russian). URL: http://docs.cntd.ru/document/902387360 (accessed 14 November 2019).

2. Dzhurinskiy A. N. Polikul'turnoye obrazovaniye v mnogonatsional'nom sotsiume [Multicultural Education in Multinational Society]. Moscow, Yurayt Publ., 2019. 257 p. (in Russian).

3. Dzhurinskiy A. N. Razvitiye obrazovaniya $v$ sovremennom mire [The development of education in the modern world]. Moscow, VLADOS Publ., 1999. 200 p. (in Russian).

4. Rasporyazheniye pravitel'stva Rossiyskoy Federatsii ot 29 dekabrya 2014 g. no. 2765-R, utverzhdayushcheye kontseptsiyu federal'noy tselevoy programmy razvitiya obrazovaniya na 2016-2020 gody [The government of the Russian Federation of 29 December 2014 no. 2765-P approving the concept of the Federal target program of education development for 2016-2020] (in Russian). URL http://government.ru/docs/16479/ (accessed 14 November 2019).

5. Federal'nyy zakon "Ob obrazovanii v RF" ot 29.12.2012 no. 273-FZ [Federal Law "On education in the Russian Federation" from 29.12.2012 no. 273-FZ] (in Russian). URL http://www.consultant.ru/document/cons_doc_LAW_140174/ (accessed 14 November 2019).

6. Kontseptsiya razvitiya polikul'turnogo obrazovaniya v Rossiyskoy Federatsi [The concept of development of multicultural education in the Russian Federation]. Moscow, 2010 (in Russian). URL: http://www.mon.gov.ru (accessed 18 November 2019).

7. Kobozeva I. S. Muzykal'noye obrazovaniye v sovremennom polikul'turnom kontekste [Musical education in a modern multicultural context]. Yaroslavskiy pedagogicheskiy vestnik - Yaroslavl Pedagogical Bulletin, 2012, vol. II, no. 3, pp. 10-13 (in Russian).

8. Kapterev P. F. Izbrannyye pedagogicheskiye sochineniya [Selected Pedagogical Compositions]. Moscow, Pedagogika Publ., 1982. 704 p. (in Russian).

9. Kobozeva I. S. Polikul'turnost' v aksiologicheskom kontekste sovremennogo muzykal'nogo obrazovaniya [Multiculturalism in the axiological context of modern music education]. Pedagogicheskaya nauka i praktika: mirovyye, rossiyskiye i regional'nyye tendentsii razvitiya: materialy mezhdunar. nauch.-prakt. konf.: 4 ch. Ch. 4 [Pedagogical science and practice: world, Russian and regional development trends: proceedings of international scientific-practical conference: in 4 parts. Part 4]. Saransk, Mordovian State Pedagogical In-t Publ., 2009. Pp. 168-171 (in Russian).

10. Kukhareva N. B. Muzykal'noye soznaniye uchitelya v protsesse polikul'turnogo obrazovaniya [Musical consciousness of a teacher in the process of multicultural education]. Pedagogika muzykal'nogo obrazovaniya: problemy i perspektivy razvitiya: materialy II Mezhdunarodnoy ochno-zaochnoy nauchno-prakticheskoy konferentsii [Pedagogy of Musical Education: Problems and Prospects of Development: materials of the II Intern. full-time scientific-practical conf.]. Nizhnevartovsk, Nizhnevart. gumanit. un-t Publ., 2009. Pp. 34-37 (in Russian).

11. Asafiev B. V. Muzykal'naya forma kak protsess [Musical form as a process]. Leningrad, Muzyka Publ., 1971. 376 p. (in Russian).

12. Kobozeva I. S., Mironova M. P., Chinyakova N. I. Communicative Competency as Teacher's Integrative Ability for Musical Communication. Asian Social Science, 2015, vol. 11, no. 8, pp. 37-43.

13. Bakhtin M. M. Tvorchestvo Fransua Rable i narodnaya kul'tura Srednevekov'ya i Renessansa [The work of Francois Rabelais and the folk culture of the Middle Ages and the Renaissance]. Moscow, Khudozhestvennaya literatura Publ., 1990. 543 p. (in Russian). 
14. Berdyayev N. A. Smysl istorii [The meaning of history]. Moscow, Mysl' Publ., 1990. 177 p. (in Russian).

15. Bibler B. C. Kul'tura: dialog kul'tur [Culture: A Dialogue of Cultures]. Voprosy filosofii, 1989, no. 6, pp. 33-38 (in Russian).

16. Nazaykinskiy Ye. V. O psikhologii muzykal'nogo vospriyatiya [On the psychology of musical perception]. Moscow, Muzyka Publ., 1972. 384 p. (in Russian).

17. Gumanitarnaya entsiklopediya [Humanitarian Encyclopedia]. Gumanitarnyye tekhnologii: analiticheskiy portal [Humanitarian Technologies: Analytical Portal] (in Russian). URL: https://gtmarket.ru/encyclopedia (accessed 14 November 2019).

18. Novikov A. M. Pedagogika: slovar' sistemy osnovnykh ponyatiy [Pedagogy: a dictionary of a system of basic concepts]. Moscow, IET Publ., 2013. 268 p. (in Russian).

19. Chinyakova N. I., Kobozeva I. S., Plokhov A. V. Muzykal'noye ispolnitel'stvo i obrazovaniye skvoz' prizmu podgotovki uchitelya [Musical performance and education through the prism of teacher training]. Yaroslavskiy pedagogicheskiy vestnik - Yaroslavl Pedagogical Bulletin, 2016, no. 3, pp. 175-180 (in Russian).

Kobozeva I. S., Mordovian State Pedagogical Institute named after M. E. Evseyev (ul. Studencheskaya, 11a, Saransk, Republic of Mordovia, Russian Federation, 430007).

E-mail: kobozeva_i@mail.ru

SPIN code: 6701-9500. 